\title{
SISTEM LOGISTIK PERTANIAN ANTAR PULAU DARI PELABUHAN MANADO
}

\author{
Abram Tombey Kandou \\ Caroline B. D. Pakasi \\ Noortje Benu
}

\begin{abstract}
The purpose of this study was to identify the existing agricultural logistics system in Manado Harbor. This research was conducted at Manado Port as the starting point and end point. The research conducted from February to May 2017. This research used primary and secondary data. Primary data is collected with a list of questions that have been prepared for Head of Port Authority Unit of Manado City Transportation Department. Secondary data are obtained, among others, from the Office of Transportation and Marine Guard Unity. Sampling was conducted using Snowball Sampling Technique. The variables that will be measured in the research of this result are: What agricultural logistics goods are held in the Port, How to store goods in Manado Port warehouse, What transportation is used for shipping agricultural logistics, How to distribution of agricultural logistics goods, How to service delivery, What is the distance between islands $(\mathrm{km})$. This research uses descriptive analysis that is to identify inter-island agricultural logistic system from Manado port and map agricultural logistic system in Manado Port. The results show that the existing logistics system in Manado Harbor has decreased not too drastically and the increase is very drastic in the year 2015. And passenger flow in the year 2011-2013 is still normal, but in 2014 and 2015 experienced a drastic increase due to passengers who soaring in that year. Logistics system in Port Manado also can be categorized pretty good because the data collection is good but still not specified agricultural goods are loaded, and for the equipment can be said to be good seen in terms of Port Manado which is still included in the category of Passenger Port, ships anchored in the Port of Manado is quite a lot and will be added over time, due to the soaring passengers between islands and goods brought. And in terms of facilities for passengers Manado Port has been very good, because the construction of infrastructure for passengers is being carried out at the time of research and development results are already visible at the time this study is completed.
\end{abstract}

Keywords: agricultural logistics system, inter-island, Manado Harbor, North Sulawesi Province

ABSTRAK

Tujuan penelitian ini adalah untuk mengidentifikasi sistem logistik pertanian yang ada di Pelabuhan Manado. Penelitian ini dilakukan di Pelabuhan Manado sebagai titik awal dan titik akhir. Penelitian dilaksanakan pada Februari - Mei 2017. Penelitian ini menggunakan data primer dan sekunder. Data primer dikumpulkan dengan daftar pertanyaan yang telah disiapkan. Wawancara dilakukan, antara lain, pada Kepala Satuan Otoritas Pelabuhan Dinas Perhubungan Kota Manado. Data sekunder diperoleh, antara lain, dari Kantor Dinas Perhubungan dan Kesatuan Penjaga Laut. Pengambilan sampel dilaksanakan dengan menggunakan Teknik Snowball Sampling. Variabel - variabel yang akan diukur di dalam penelitian hasil ini yaitu: Barang logistik pertanian apa saja yang diadakan di Pelabuhan, Cara penyimpanan barang di gudang Pelabuhan Manado, Transportasi apa yang digunakan untuk pengiriman logistik pertanian, Bagaimana cara pendistribusian barang logistik pertanian tersebut, Bagaimana cara pelayanan pengantarannya, Berapa jarak antar pulau $(\mathrm{km})$. Penelitian ini menggunakan Analisis Deskriptif yaitu untuk mengidentifikasi sistem logistik pertanian antar pulau dari Pelabuhan Manado dan memetakan sistem logistik pertanian di Pelabuhan Manado. Hasil penelitian menunjukkan bahwa sistem logistik yang ada di Pelabuhan Manado mengalami penurunan yang tidak terlalu drastis dan kenaikan yang sangat drastis di tahun 2015. Dan Arus penumpang di tahun 2011-2013 masih normal, tetapi di tahun 2014 dan 2015 mengalami kenaikan yang drastis dikarenakan penumpang yang melonjak di tahun tersebut. Sistem logistik yang ada di Pelabuhan Manado juga sudah bisa dikategorikan lumayan baik karena pendataan barangnya sudah bagus namun belum dirincikan barang pertanian yang dimuat, dan untuk peralatan sudah bisa dikatakan baik dilihat dari segi Pelabuhan Manado yang masih masuk dalam kategori Pelabuhan Penumpang, karena kapal-kapal yang berlabuh di Pelabuhan Manado sudah lumayan banyak dan akan bertambah seiring dengan berjalannya waktu, dikarenakan semakin melonjaknya penumpang antar pulau dan barang-barang yang dibawa. Dan untuk dari segi fasilitas untuk penumpang Pelabuhan Manado sudah sangat baik, dikarenakan pembangunan infrastruktur untuk penumpang sedang dilaksanakan pada saat penelitian dilakukan dan hasil pembangunan tersebut sudah nampak pada saat penelitian ini selesai.

Kata Kunci: sistem logistik pertanian, antar pulau, Pelabuhan Manado, Provinsi Sulawesi Utara 


\section{PENDAHULUAN}

\section{Latar Belakang}

Sistem logistik merupakan suatu sistem yang menangani aktivitas yang berhubungan dengan penyampaian barang dari suatu titik asal ke titik tujuan. Dalam pengertian yang lebih luas logistik diartikan sebagai proses perencanaan, implementasi dan pengawasan yang efektif dan efisien terhadap aliran biaya, material, dan informasi dari titik asal ke titik yang membutuhkan dengan tujuan memenuhi kebutuhan konsumen (Ballou, 1992).

Logistik dalam perkembangannya hingga kini sudah merupakan ilmu yang mendapat perhatian khusus mengingat sejarah pertumbuhan ekonomi yang semakin kompleks seperti produktivitas barang-barang yang dihasilkan pabrik atau perusahaan, bagaimana penyalurannya dan penyimpanannya serta pengelolaan hasil produk secara menyeluruh memerlukan penanganan khusus dan serius. Untuk mencapai hasil yang efisien dan efektivitas semua itu mutlak memerlukan pengorganisasian yang baik atau sering diistilahkan dengan manajemen logistik yang terpadu sehingga tidak terjadi ketimpangan dalam melaksanakan kegiatannya (Chandra, 2013)

Dalam Cetak Biru Pengembangan Sistem Logistik Nasional (Perpres No.26 Tahun 2012), logistik didefinisikan sebagai bagian dari rantai pasok (supply chain) yang menangani arus barang, informasi, dan uang melalui proses pengadaan (procurement), penyimpanan (warehousing), transportasi (transportation), distribusi (distribution), dan pelayanan pengantaran (delivery services). Adapun penyusunan sistem logistik ditujukan untuk meningkatkan keamanan, efisiensi, efektifitas pergerakan barang, informasi dan uang mulai dari titik asal (point of origin) sampai dengan titik tujuan (point of destination) sesuai dengan jenis, kualitas, jumlah, waktu dan tempat yang dikehendaki konsumen.

Kontribusi sektor pertanian dan agribisnis terhadap ekonomi Indonesia cukup nyata, khususnya dalam penyerapan tenaga kerja pedesaan dan ketahanan pangan. Diperkirakan terdapat 43 juta orang bekerja di sektor ini, dan menunjukkan penurunan selama lima tahun terakhir, yakni dari $43.97 \%$ di tahun 2005 menjadi $41.18 \%$ di tahun 2009 , hingga hanya menyerap $36 \%$ tenaga kerja Indonesia pada tahun 2011(BPS, 2012). Namun demikian, kontribusi sektor ini terhadap nilai tambah, dan $5.16 \%$ dari total produksi Indonesia (PDB), akan tetapi secara nilai (atas Dasar Harga Konstan tahun 2000) ratarata terjadi peningkatan sebesar $3.3 \%$ per tahun (BPS 2012) (Fizzanty ${ }^{2}$ dan Kusnandar, 2012).

Sistem logistik di Manado saat ini perlu perhatian khusus, dikarenakan kurangnya fasilitas yang menunjang untuk pengiriman barang maupun masuknya barang. Contohnya di Pelabuhan Manado belum ada kargo yang dapat mengirimkan barang dengan cepat dan bisa menekan biaya pengiriman ke antar pulau yang masih terbilang mahal di Manado. Maka dari itu di pulau-pulau yang dikirimkan komoditi pertanian harganya bisa $2 x$ lipat dari yang ada di Manado, dan juga sebaliknya komoditi pertanian yang dikirimkan dari pulau-pulau ke Manado tinggi juga harganya. Pelabuhan Manado saat ini masuk dalam kategori pelabuhan penumpang dan belum ada tanda-tanda untuk menjadi pelabuhan kargo.

Sistem informasi untuk logistik di Pelabuhan Manado ini juga masih terbatas, dikarenakan pengiriman barang yang dilakukan hanya melalui penumpang tidak disortir atau dirincikan dengan baik. Data yang di dapat tidak tersedia barang komoditi pertanian apa saja yang diterima. Data itu juga sudah dihitung secara langsung di daftar barang. Seharusnya perincian barang sangat perlu agar data yang dikirim dan diterima bisa tepat sasaran dan pada saat dibutuhkan bisa didapat dengan mudah.

\section{Definisi Logistik}

Aktivitas logistik adalah menyediakan sistem dengan produk yang tepat, di lokasi yang tepat, pada waktu yang tepat (right product, in the right place, at the right time) dengan mengoptimasikan pengukuran performansi yang diberikan contohnya meminimalisir total biaya operasional dan memenuhi kualifikasi yang diberikan sesuai dengan kemampuan dari klien dan sesuai dengan kualitas pelayanan. (Ghiani et al., 2004).

Logistik merupakan integrasi atau gabungan dan interaksi antara informasi, transportasi, inventori, gudang (warehouse), penanganan material (material handling), dan pengepakan (packaging), di mana masing-masing bagian memiliki dorongan kerja yang berbeda yang seluruhnya akhirnya menjadi kombinasi dalam bentuk manajemen (Bowersox and Closs, 1996).

Logistik memegang peranan penting dalam penentuan daya saing suatu organisasi. 
Daya saing dapat dilihat dari dua dimensi yaitu keunggulan nilai (pelanggan bukan membeli produk tetapi membeli nilai) dan keunggulan biaya (setiap kegiatan memerlukan biaya). Secara sederhana bila masing-masing dimensi mempunyai skala tinggi dan rendah pada nilai dan biaya. Sementara kondisi "lebih murah" terjadi bila organisasi mempunyai keunggulan biaya. Sebuah organisasi akan disebut "lebih baik" bila mempunyai keunggulan nilai yang dapat memuaskan pelanggannya. (Simatupang dan Sianipar, 2014)

Secara umum kegiatan logistik terdiri dari 2 (dua) kegiatan yaitu kegiatan pergerakan (move) dan kegiatan penyimpanan (store), sehingga jika kedua kegiatan ini direncanakan dan dikendalikan secara ketat, maka masalah sistem logistik secara keseluruhan akan dapat terselesaikan dengan baik. Dua kegiatan utama tersebut diurai menjadi beberapa kegiatan yaitu pemrosesan pesanan, transportasi, persediaan, penanganan barang, struktur fasilitas dan sistem informasi dan komunikasi. Ketujuh kegiatan itu disebut juga sebagai bauran kegiatan logistik (logistics activity mix) dimana semua kegiatan tersebut tidak dapat dihindarkan keberadaannya dalam sebuat sistem rantai pasok (Supply Chain System).

Gambar 1 : Sistem Logistik Secara Sederhana

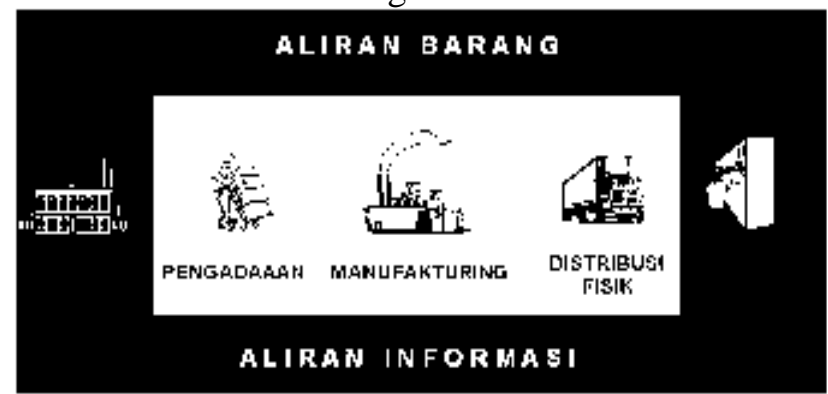

Pemasok - Pengadaan - Manufakturing Distribusi Fisik - Pelanggan

Sumber: Setijadi, 2009

Pada Prinsipnya, dalam suatu sistem logistik terdapat dua aliran utama. Aliran pertama adalah aliran barang dari pemasok ke pabrik atau manufakturing, hingga ke pelanggan. Berlawanan dengan aliran barang, terdapat aliran informasi yang mengalir dari pelanggan, ke pabrik, hingga ke pemasok.

Sebagai sebuah sistem, logistik terdiri atas beberapa subsistem atau komponenkomponen utama, yaitu Persediaan, Pergudangan, Transportasi, dan Sistem Informasi.
Gambar 2 : Keterkaitan Komponen Utama Pembentuk Sistem Logistik.

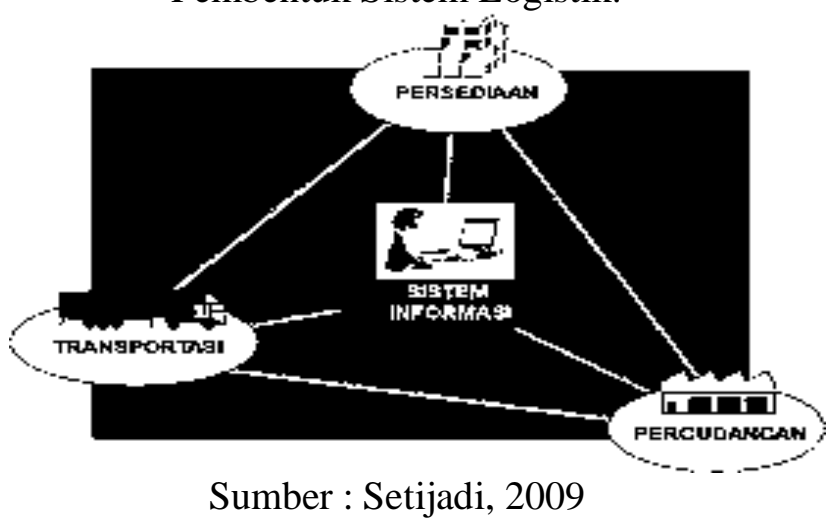

Sistem Logistik

Defenisi sistem logistik secara umum adalah menangani semua aktifitas yang berhubungan dengan penyampaian barang atau produk dari titik asal menuju ke titik tujuan. Titik asal (point of origin) bertindak sebagai produsen karena berfungsi sebagai pemasok barang, baik sebagai penghasil (memproduksi barang) atau penyalur barang ke pemakai selanjutnya, sedangkan titik tujuan (point of destination) bertindak sebagai konsumen, baik dipakai secara langsung ataupun disalurkan kemudian. (Sinaga, 2008).

Sistem logistik tersusun atas fasilitasfasilitas yang terhubung dengan jasa pelayanan transportasi. Sistem ini membahas mengenai bagaimana suatu material diproses, manufaktur, disimpan, diseleksi, untuk kemudian dijual atau dikonsumsi. Sistem logistik ini merupakan pembahasan mengenai proses manufaktur dan perakitan, pergudangan, pendistribusian, titik/poin pengalihan angkutan, terminal transportasi, dan penjualan eceran. (Ghiani G., 2004).

Gambar 3 : Skema Sistem Logistik

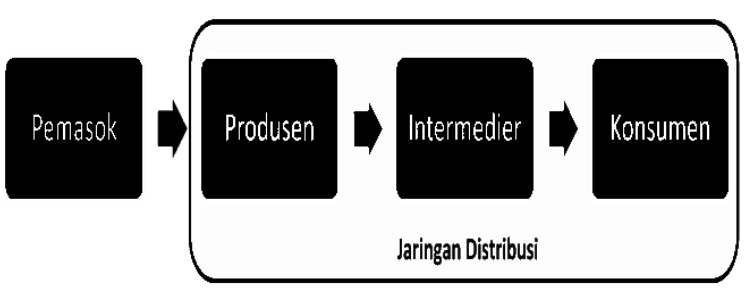

Sumber: Senator, 2012 
Berdasarkan skema tersebut diatas dapat digambarkan bahwa sistem logistik merupakan sistem yang membahas mengenai keterkaitan antara entitas/pelaku dalam sebuah kegiatan logistik yang terintegrasi, dari pemasok hingga konsumen dalam masing-masing jaringan distribusi untuk menggerakkan barang/jasa. Adapun yang menjadi obyek dari sistem logistik dapat berupa barang jadi, barang setengah jadi, maupun bahan baku. Untuk memaksimalkan nilai sistem logistik yang diupayakan, diperlukan variasi rencana mengenai pengambilan keputusan untuk setiap tahapan aktivitasnya. Perencanaan sistem logistik yang mendukung juga mempengaruhi desain dan operasional sistem logistik yang akan diberlakukan guna menciptakan efisiensi dan efektifitas produksi suatu barang dan jasa (Chandra, 2013).

\section{Sistem Logistik Pertanian}

Pembangunan pertanian memiliki posisi yang strategis dalam pembangunan perekonomian nasional. Peran strategis tersebut berupa kontribusi nyata melalui pembentukan kapital, penyediaan bahan pangan, bahan baku industri, pakan dan bio-energi, penyerap tenaga kerja, sumber devisa negara, dan sumber pendapatan. Sektor pertanian menjadi tumpuan utama bagi masyarakat Indonesia dalam memenuhi pangannya (food security) serta menjadi tumpuan utama bagi penghidupan sebagian besar masyarakat Indonesia yang tinggal di perdesaan. Dengan peran tersebut, pembangunan pertanian yang optimal akan mampu mewujudkan kemandirian dan daya saing bangsa Indonesia dalam era globalisasi. (Perdana, 2016).

Dalam Mewujudkan sistem logistik pertanian di atas perlu dilakukan upaya bersama seluruh pemangku kepentingan dari mulai pemerintah, asosiasi industri logistik, akademisi, dan pelaku pertanian. Sistem logistik sepatutnya mengkaitkan level makro (kebijakan pemerintah), level meso (pengembangan klaster/sentra pertanian), dan level mikro (pelaku pertanian). Pada level makro diperlukan kerangka kelembagaan berupa regulasi khusus pengembangan sistem logstik pertanian dari mulai kebun sampai ke pasar. Pada level meso, perlu dilakukan pembangunan infrastruktur logistik pertanian di pedesaan bekerjasama dengan pelaku logistik yang akan mengembangkan berbagai layanan jasa logistik pertanian di pedesaan. Pada level mikro, perlu dilakukan upaya sistematis untuk mengkaitkan pelaku pertanian di pedesaan, terutama petani dengan pelaku pasar (ritel modern, eksportir, pasar induk, industri pengolahan, dan jasa pangan). (Perdana, 2016).

Logistik untuk produk pertanian termasuk hortikultura cukup kompleks baik dari sisi produksi, distribusi dan konsumsi. Hal tersebut dikarenakan sistem logistik produk hortikultura memiliki karakteristik tertentu yang dipengaruhi oleh sistem produksi, sifat produk dan konsumen. Oleh karena itu sistem logistik untuk produk hortikultura memerlukan penanganan khusus dan berbeda dari produk manufaktur. (Fizzanty dan Kusnandar, 2012)

Mena and Steven (2010) menjelaskan beberapa karakteristik khusus dari produk pertanian termasuk hortikultura, yaitu :

1) Musiman: Produk pertanian memiliki sifat musiman baik pada sistem produksi maupun konsumsinya.

2) Keamanan, nutrisi dan kesehatan: Produk pangan akan berdampak langsung pada tubuh seseorang yang mengkonsumsi. Oleh karena itu faktor keamanan, kualitas, ketelusuran menjadi isu penting.

3) Umur produk pendek dan rentan rusak: Sifat biologis produk pertanian mengakibatkan umurnya pendek dan rentan terhadap kerusakan yang diakibatkan oleh fisik atau kimia.

4) Dampak terhadap lingkungan: Sistem pertanian beresiko terhadap lingkungan karena menggunakan banyak lahan, air, dan energi.

Sementara itu Vorst, et al (2005) menjelaskan karakteristik logistik produk pertanian berdasarkan pelaku dalam rantai pasok, yaitu :

1) Petani

- Periode produksi lama.

- Produksi bersifat musiman.

- Kualitas hasil dan volume yang dipasok bervariasi.

2) Pedagang (bandar/ritel)

- Bervariasinya kualitas dan volume pasokan dari petani. 
- Pasokan bersifat musiman

- Memerlukan pengkondisian untuk transportasi dan ruang penyimpanan.

3) Industri

- Variabel dalam proses sangat berpangaruh terhadap kuantitas da kualitas hasil karena pengaruh sifat biologi yang bervariasi, musim, cuaca, hama, dan kerusakan biologi lainnya.

- Dibutuhkan waktu untuk menunggu tes kualitas (karantina).

- Ruang penyimpanan dan buffer harus khusus sesuai dengan sifat bahan baku atau produk

- Membutuhkan ketelusuran dalam proses produksi mengingat pentingnya faktor kualitas dan lingkungan.

Menurut Wilkinson J, R. Rocha (2008), subsistem manufaktur dan pemasaran berbasis pertanian di Indonesia belum menunjukkan kinerja yang optimal. Hal tersebut dapat terlihat dari rasio perbandingan antara subsistem pertanian dengan subsistem manufaktur dan pemasaran berbasis hasil pertanian Indonesia sebesar 1,65. Kondisi tersebut lebih rendah dibandingkan dengan Thailand yang memiliki rasio 3,91.

Adapun 5 tahap pengembangan model sistem logistik pertanian (Promodel corporation, 2011) :

1) Rencana studi : Rencana studi dilakukan untuk merancang dan mengembangkan model sistem logistik.

2) Mendefinisikan sistem : Mengamati lokasi untuk memperoleh beberapa informasi mengenai lokasi yang spesifik, waktu perjalanan dan jarak pengiriman produk.

3) Merancang Model : Model yang dirancang meliputi ruang lingkup kegiatan logistik, mulai dari transportasi, penanganan produk kemudian pendistribusian produk kepada konsumen. Setelah model dibangun, tahap selanjutnya melakukan verifikasi dan validasi. Verifikasi dilakukan dengan pengujian model dapat dijalankan tanpa kesalahan. Validasi dilakukan dengan analisis sensitivitas, mencoba beberapa inerval waktu simulasi untuk melihat hasilnya.

4) Menjalankan simulasi : Setelah model valid, mencoba beberapa skenario kemudian mencoba beberapa kombinasi sumber daya yang dapat menyelesaikan proses penanganan sesuai dengan volume permintaan untuk interval waktu tertentu, dan mengamati utilitas sumber daya.

5) Analisis Hasil : Hasil simulasi dianalisis untuk menciptakan model sistem logistik terbaik. Biaya logistik dari model terbaik juga dianalisis menggunakan perhitungan matematis.

\section{Pengertian Pelabuhan}

Pelabuhan adalah tempat yang terdiri dari daratan dan perairan di sekitarnya dengan batas-batas tertentu sebagai tempat kegiatan pemerintahan dan kegiatan ekonomi dipergunakan sebagai tempat kapal bersandar, berlabuh, naik turun penumpang dan/atau bongkar muat barang yang dilengkapi dengan fasilitas keselamatan pelayaran dan kegiatan penunjang pelabuhan serta sebagai tempat perpindahan intra dan antar moda transportasi (Suyono, 2005).

$$
\text { Selanjutnya, Suyono }
$$
menyatakan bahwa kepelabuhanan meliputi segala sesuatu yang berkaitan dengan kegiatan penyelenggaraan pelabuhan dan kegiatan lainnya dalam melaksanakan fungsi pelabuhan untuk menunjang kelancaran, keamanan, dan ketertiban arus lalu lintas kapal, penumpang dan/atau barang, keselamatan berlayar, serta tempat perpindahan intra dan/atau antar moda transportasi.

\section{Jenis-Jenis Pelabuhan.}

Menurut Suyono (2005), jenis-jenis pelabuhan dapat dibedakan berdasarkan : (1)Alamnya, (2)Pelayanannya, (3)Lingkup pelayaran yang dilayani, (4)Kegiatan perdagangan luar negeri, (5)Kapal yang diperbolehkan singgah, (6)Wilayah pengawasan bea cukai, (7) Kegiatan pelayarannya, (8) Perannya dalam pelayaran.

1) Berdasarkan Alamnya terdiri dari dua bagian yaitu : (a)Pelabuhan Terbuka, adalah pelabuhan dimana kapal-kapal bisa masuk dan merapat secara langsung tanpa bantuan pintu-pintu air. (b)Pelabuhan Tertutup, adalah pelabuhan dimana kapal-kapal yang masuk harus melalui beberapa pintu-pintu air.

2) Berdasarkan Pelayanannya terdiri dari dua bagian yaitu : (a)Pelabuhan Umum, adalah pelabuhan yang diselenggarakan untuk kepentingan masyarakat umum. (b)Pelabuhan 
Khusus, adalah pelabuhan yang dikelola untuk kepentingan sendiri guna menunjang kegiatan tertentu.

3) Berdasarkan Lingkup Pelayaran yang Dilayani terdiri dari 5 bagian yaitu : (a)Pelabuhan Hub Internasional, adalah pelabuhan utama primer yang berfungsi melayani kegiatan dan alih muatan angkutan laut nasional dan internasional dalam jumlah besar dan jangkauan pelayaran yang sangat luas serta merupakan simpul dalam jaringan transportasi laut internasional. (b)Pelabuhan Internasional, adalah pelabuhan utama sekunder laut nasional dan internasional dalam jumlah besar dan jangkauan pelayanan yang luas serta merupakan simpul dalam jaringan transportasi laut internasional. (c)Pelabuhan Nasional, adalah pelabuhan utama tersier yang berfungsi melayani kegiatan dan alih muat angkutan laut nasional dan internasional dalam jumlah menengah serta merupakan simpul dalam jaringan transportasi tingkat provinsi. (d)Pelabuhan Regional, adalah pelabuhan pengumpan primer yang berfungsi melayani kegiatan dan alih muatan angkutan laut nasional dalam jumlah yang relatif kecil serta merupakan pengumpan dari pelabuhan utama. (e)Pelabuhan Lokal, adalah pelabuhan pengumpan sekunder yang berfungsi melayani kegiatan angkutan laut regional dalam jumlah kecil serta merupakan pengumpan pada pelabuhan utama dan/atau pelabuhan regional.

4) Berdasarkan Kegiatan Perdagangan Luar Negeri terdiri dari dua bagian yaitu : (a)Pelabuhan Impor, adalah pelabuhan yang melayani masuknya barang-barang dari luar negeri. (b)Pelabuhan Ekspor, adalah pelabuhan yang melayani penjualan barangbarang ke luar negeri.

5) Berdasarkan Kapal yang Diperbolehkan Singgah terdiri dari dua bagian yaitu : (a) Pelabuhan Laut, adalah pelabuhan yang terbuka bagi perdagangan luar negeri dan dapat disinggahi oleh kapal-kapal dari Negara sahabat. (b) Pelabuhan Pantai, adalah pelabuhan yang tidak terbuka untuk perdagangan dengan luar negeri dan hanya dapat dipergunakan oleh kapal-kapal dari Indonesia.

6) Berdasarkan Wilayah Pengawasan Bea Cukai terdiri dari dua bagian yaitu : (a)Custom Port, adalah pelabuhan yang berada di bawah pengawasan Bea Cukai. (b)Free Port, adalah pelabuhan yang berada di luar pengawasan Bea Cukai.

7) Berdasarkan Kegiatan Pelayarannya terdiri dari tiga bagian yaitu : (a)Pelabuhan Samudera, adalah pelabuhan Tanjung Priok di Jakarta dan Tanjung Perak di Surabaya. (b)Pelabuhan Nusantara atau Pelabuhan Interinsuler, adalah pelabuhan Banjarmasin di Kalimantan Selatan. (c)Pelabuhan Rakyat, adalah pelabuhan Sunda Kelapa di Pasar Ikan, Jakarta.

8) Berdasarkan Perannya dalam Pelayaran terdiri dari dua bagian yaitu : (a)Pelabuhan Transito, adalah pelabuhan yang mengerjakan transhipment cargo. (b) Pelabuhan Ferry, adalah pelabuhan penyebrangan.

\section{Rumusan Masalah}

Rumusan masalah dalam penelitian ini adalah apakah sistem logistic pertanian di Pelabuhan Manado sudah terstruktur dan sesuai standar yang diterapkan pemerintah dan yang diharapkan oleh masyarakat ?

\section{Tujuan Penelitian}

Tujuan penelitian ini adalah untuk mengidentifikasi sistem logistik pertanian yang ada di Pelabuhan Manado

\section{Manfaat Penelitian}

Manfaat dari penelitian ini agar sistem logistik pertanian di Pelabuhan Manado dapat berkembang dan memiliki feedback positif terhadap pemerintah bagian kepelabuhanan dan untuk saya sendiri agar lebih mengetahui tentang sistem logistik pertanian di pelabuhan. Manfaat penelitian ini juga agar Pelabuhan Manado dapat memiliki kargo yang dapat mengirimkan barang pertanian dan supaya mendapat fasilitas pendukung untuk menunjang sistem logistik tersebut.

\section{METODOLOGI PENELITIAN}

\section{Waktu dan Tempat Penelitian}

Penelitian ini dilakukan di Pelabuhan Manado sebagai titik awal dan titik akhir. Penelitian dilaksanakan pada Februari - Mei 2017 


\section{Metode Penelitian}

Metode yang digunakan dalam penelitian ini adalah metode survei dengan cara mengambil data primer dan data sekunder. Data primer diperoleh melalui daftar pertanyaan yang telah disiapkan untuk Kepala Satuan Otoritas Pelabuhan Dinas Perhubungan Kota Manado. Data sekunder diperoleh dari Kantor Dinas Perhubungan, Kesatuan Penjaga Laut dan Instansi Terkait Lainnya.

\section{Metode Pengambilan Sampel}

Pengambilan sampel dilaksanakan dengan menggunakan Teknik Snowball Sampling. Teknik ini adalah metode pengambilan sampel dengan secara berantai (Multi Level). Mencari contoh sampel dari sampel yang kita inginkan, kemudian dari sampel yang didapat dimintai partisipasinya untuk memilih komunitasnya sebagai sampel lagi. Seterusnya sehingga sampel yang kita inginkan terpenuhi.

\section{Konsep Pengukuran Variabel Hasil}

Variabel - variabel yang akan diukur di dalam penelitian hasil ini yaitu :

1. Barang logistik pertanian apa saja yang diadakan di Pelabuhan

2. Cara penyimpanan barang di gudang Pelabuhan Manado

3. Transportasi apa yang digunakan untuk pengiriman logistik pertanian

4. Bagaimana cara pendistribusian barang logistik pertanian tersebut

5. Bagaimana cara pelayanan pengantarannya

6. Berapa jarak antar pulau (Km)

\section{Analisis Data}

Dalam penelitian ini menggunakan Analisis Deskriptif yaitu untuk mengidentifikasi sistem logistik pertanian antar pulau dari Pelabuhan Manado dan memetakan sistem logistik pertanian di Pelabuhan Manado.

\section{HASIL DAN PEMBAHASAN}

\section{Gambaran Umum Pelabuhan}

\section{Sejarah Singkat Pelabuhan Manado}

Pelabuhan Manado adalah Pelabuhan yang berada di Ibukota Provinsi Sulawesi Utara sebagai Pusat kegiatan Pemerintahan, Perdagangan, Pendidikan dan Pariwisata dibangun sejak Tahun 1917 oleh Pemerintah Hindia Belanda yang sampai saat ini eksistensinya masih dipertahankan seperti letak Geografis dan juga Fasilitas Pelabuhan yang masih dapat dimanfaatkan.

Terletak pada posisi : 01 ${ }^{\circ}-30^{\prime}-$ 02'LU/124-50'-12"BT yang berada pada Teluk Manado yang berhadapan dengan Pulau Manado Tua, Bunaken dan beberapa PulauPulau kecil lainnya. Pelabuhan Manado (Khususnya pada kolam Pelabuhan) dapat dimasuki oleh Kapal-Kapal Pelayaran dalam negeri, Pelayaran rakyat dan jenis kapal lainnya yang mempunyai Draft sampai dengan 4 Meter, sedangkan untuk Kapal-Kapal berukuran besar berlabuh Jangkar diluar kolam Pelabuhan karena tidak tersedia fasilitas yang memadai.

Perkembangan dari tahun ke tahun Pelabuhan Manado semakin berkembang yang dapat dilihat dari jumlah bongkar/muat barang, turun naik penumpang dan kunjungan kapal. Untuk itu, sesuai dengan Keputusan Menteri Perhubungan No.53 Tahun 2002 tanggal 29 Agustus 2002 tentang Tatanan Kepelabuhanan Nasional, ditetapkan Pelabuhan Manado sebagai Pelabuhan Nasional, selain daripada itu melalui KM No.62 Tahun 2002 dirubah menjadi Keputusan Menteri KM.17 Tahun 2004 dan mengalami perubahan kembali menjadi Kepmenhub No.9 Tahun 2009 tentang Organisasi dan Tata Kerja Kantor Administrator Pelabuhan Manado, maka Kantor Administrator Pelabuhan Manado ditetapkan sebagai Kantor Adpel Kelas III.

Pelabuhan Manado merupakan simpul utama dari Kepulauan Sangihe, Talaud dan Sitaro dan juga daerah Sulawesi Tengah, Maluku Utara dan Perairan Indonesia Timur pada umumnya sebagai Pelabuhan yang berada di Pusat Pemerintahan Sulawesi Utara mengakibatkan arus penumpang dari dan ke daerah-daerah sekitarnya sangatlah dominan yang sangat berkaitan dengan mobilisasi arus barang dari dan ke daerah hinterlandnya.

Disamping komoditi Hinterland Provinsi Sulawesi Utara, yang menjadikan andalan Pelabuhan Manado adalah barangbarang muatan dari wilayah disekitar Pelabuhan Manado yang masuk ke wilayah Kawasan 
Timur Indonesia (KTI), seperti Papua, Maluku, Sulteng dan sekitarnya sehingga Manado dapat menjadi Pelabuhan Transit Nasional.

\section{Peralatan Yang Masih Diperlukan Untuk Pelabuhan Manado}

Untuk memperdayakan Pelabuhan Manado secara menyeluruh dan terpadu masih diperlukan : (a)Sumber Daya Manusia (SDM) yang mampu menangani kemajuan teknologi disegala bidang; (b)Pembangunan sarana dan prasarana Pelabuhan diantaranya Dermaga dan Breakwater; (c)Fasilitas Pelabuhan antara lain : Dermaga, Gudang, Lapangan Penumpukan, Terminal Penumpang, Luas Lingkungan Kerja, Alur Pelayaran, Kolam Pelabuhan, Fasilitas Listrik, Bahan Bakar, TKBM dan Bagasi, Fasilitas Perbaikan Kapal, Kapasitas Bongkar/Muat. (d)Fasilitas Keselamatan Pelayaran antaran lain : Mercusuar, Lampu Pelabuhan, Stasiun Radio Pantai, Speed Boat, Speed Boat Marine Surveyo

\section{Variabel yang dianalisis di Lapangan}

\section{Definisi Logistik Dikaitkan Dengan Pelabuhan Manado \\ Definisi sistem logistik yang} berhubungan dengan pelabuhan khususnya di pelabuhan Manado ini adalah berdasarkan dengan apa yang saya teliti di lapangan. Ternyata, deskripsi oleh para ahli tentang sistem logistik berhubungan dengan penyampaian barang dari suatu tempat ketempat lain ini berkesinambungan juga dengan sistem logistik yang ada di Pelabuhan Manado juga, akan tetapi di pelabuhan Manado bukan merupakan pelabuhan barang atau pelabuhan cargo, melainkan pelabuhan penumpang yang hanya mengirimkan barang dari penumpang tersebut dan di tampung di lambung kapal atau yang biasa disebut Bagasi Kapal

\section{Waktu Keberangkatan Kapal-Kapal}

Jam Keberangkatan kapal-kapal penumpang yang ada di pelabuhan Manado dari pukul 07.00 Malam dan sampai di tempat tujuan pada pukul 05.00 pagi, tergantung dengan jauh dekatnya tempat yang ditujukan. Contohnya seperti perjalanan ke Siau lebih cepat 2-3 jam dari perjalanan ke Sanger.

\section{Jumlah Barang Dalam Pengiriman}

Jumlah barang dalam satu kali pengiriman tergantung dengan banyaknya pesanan atau titipan dari orang kenalan maupun orang lain yang membutuhkan barang pertanian tersebut, tapi banyak juga penumpang yang berprofesi sebagai pedagang yang mengambil barang dari Manado maupun sekitaran Manado untuk dibawa ke pulau. Sebaliknya juga dari pulau-pulau ada juga pedagang maupun penumpang yang membawa komoditi pertanian dengan alasan yang sama.

\section{Harga Barang Pertanian}

Barang pertanian yang dijual juga bervariasi seperti harga cabe dijual di sekitaran harga Rp.100.000/kg ,bawang Rp.8000 dan tomat $\mathrm{Rp} 8.000 / \mathrm{kg}$. Barang pertanian ini juga tergantung dari harga pasar kalau misalnya cabe pada Musim Hujan kebanyakan rusak atau busuk karena banyak penyakit tanaman yang menyerang tanaman cabe, otomatis harga cabe yang biasanya Rp100.000/kg bias menjadi Rp.120.000/kg karena susahnya cabe untuk didapatkan.

\section{Barang Pertanian Yang Banyak Dikirimkan \\ Barang pertanian yang banyak dikirimkan} dari Manado ke Pulau-pulau maupun sebaliknya adalah bawang, rica ,tomat (Rica yang disebutkan adalah cabe). Bawang, rica, tomat ini banyak dikirimkan, karena komoditi tersebut sangat diperlukan sehari-hari untuk kebutuhan seperti memasak.

\section{Cara Pengiriman Barang Pertanian}

Komoditi pertanian yang dibawa dari Manado kepulau-pulau dan sebaliknya dibawa dengan cara hanya dititipkan ke kerabat atau orang lain yang akan ke Manado maupun ke pulau-pulau, nanti di tempat tujuan sudah ada orang yang menunggu untuk membantu menjual maupun membawa barang pertanian tersebut ke suatu tempat ,tetapi orang ini kebanyakan bukan pihak ketiga tetapi keluarga yang membantu untuk membawa ke rumah atau dijual.

\section{Jarak Antar Pulau}

Jarak antar pulau yang di dapati dari Manado ke Siau Ditempuh sejauh 146km, Manado sampai Tahuna ditempuh dengan jarak $244 \mathrm{~km}$, sedangkan Manado sampai Talaud bisa ditempuh dengan jarak $345 \mathrm{~km}$. 


\section{Grafik Data}

Di bawah ini ada gambar grafik Barang yang di ambil dari tahun 2011 sampai dengan tahun 2015. Grafik yang ada di bawah ini mengacu

a. Tahun 2011 Jumlah barang berada pada angka 83.569 di grafik 0.83 .

b. Tahun 2012 Jumlah barang berada pada angka 82.917 di grafik 0.829 .

c. Tahun 2013 Jumlah barang berada pada angka $68.567,8$ di grafik 0.685 .

d. Tahun 2014 Jumlah barang berada pada angka 50.156,10 di grafik 0.501.

e. Tahun 2015 Jumlah barang berada pada angka 802.128 di grafik 4.802.1

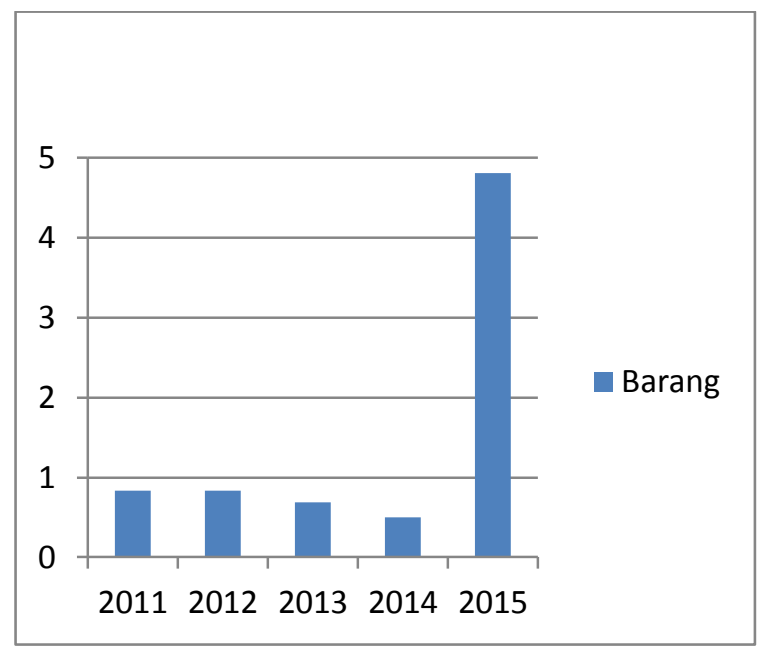

Gambar 4 : Grafik Barang Dari Tahun 2011-2015

Jadi bisa disimpulkan bahwa pada tahun 2011 sampai dengan tahun 2014 muatan barang yang ada di kapal mengalami penurunan yang tidak terlalu drastis atau bisa dikatakan normal, tapi pada saat tahun 2015 mengalami peningkatan yang signifikan,karena barang-barang muatan yang dibawa sudah termasuk barang logistik pertanian banyak dibawa di tahun 2015

Arus penumpang juga mempengaruhi pembawaan barang yang ada di kapal-kapal karena Pelabuhan Manado masih kategori Pelabuhan Penumpang, maka dari itu barangbarang logistik yang dibawa masih dihitung dalam barang bawaan penumpang dan barang-barang tersebut tidak dirincikan secara detail, hanya masuk pada data barang saja. Grafik di bawah ini.

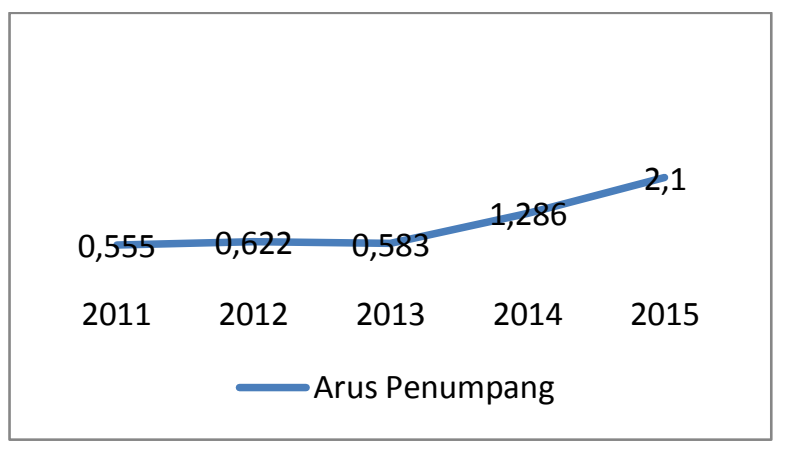

Gambar 5 : Grafik Arus Penumpang Tahun 20112015

a. Tahun 2011 Jumlah penumpang berada di angka 555.288 di grafik 0.555 .

b. Tahun 2012 Jumlah penumpang berada di angka 622.040 di grafik 0.622 .

c. Tahun 2013 Jumlah penumpang berada di angka 583.477 di grafik 0.583 .

d. Tahun 2014 Jumlah penumpang berada di angka 1.286.426 di grafik 1.286.

e. Tahun 2015 Jumlah penumpang berada di angka 2.100.527 di grafik 2.1.

Tapi,arus penumpang pada pada tahun 2011 berada pada kisaran angka 555.288,tahun 2012 di angka 622.040,tahun 2013 di angka 583.477, tahun 2014 naik secara signifikan di angka 1.286.426, dan terakhir di tahun 2015 naik juga di angka 2.100.527. Agar lebih jelasnya bisa dilihat di grafik.

Pada Tabel 1 bisa dilihat bahwa jadwal pelayaran kapal ada 17 dengan tujuan berbeda-beda. Pertama, KM.Karya Indah yang berlayar dari Manado ke Tahuna pada hari Senin, sedangkan dari Manado ke Lirung setiap hari Rabu dan Jumat. Kedua, KM.Marina Bay I berlayar dari Manado ke Siau dan Ke Tahuna dalam satu kali perjalanan terjadi pada setiap hari Senin, Rabu dan Jumat. Ketiga, KM.Express Bahari 2E berlayar dari Manado ke Tagulandang ke Siau dan Tahuna dalam satu kali perjalanan setiap hari Senin, Rabu dan Jumat. Keempat, KM.Majestic Kawanua II berlayar dari Manado ke Tagulandang ke Siau dan ke Tahuna dalam satu kali perjalanan setiap hari Selasa, Kamis dan Sabtu. Kelima, KM.Majestic Kawanua berlayar dari Manado ke Tagulandang ke Siau dan ke Tahuna dalam satu kali perjalanan setiap hari Senin, Rabu dan Jumat. Keenam, KM.Elizabeth III berlayar dari Manado ke Tobelo setiap hari Senin. Ketujuh, KM.Geovani berlayar dari Manado ke Ternate setiap hari Selasa. Kedelapan, KM.Bunda Maria 
berlayar dari Manado ke Ternate setiap hari Minggu. Kesembilan, KM.Agil Pratama 04 berlayar dari Manado ke Ternate setiap hari Senin. Kesepuluh, KM.Permata Bunda berlayar dari Manado ke Ternate setiap hari Minggu. Kesebelas, KM.Prima Oasis berlayar dari Manado ke Tagulandang ke Siau dan ke Tahuna dalam 1 kali perjalanan setiap hari Selasa, Kamis dan Minggu. Keduabelas, KM.Marin Teratai berlayar dari Manado ke Ternate setiap hari Rabu. Ketigabelas, KM.Holly Mary berlayar dari Manado ke Talaud setiap hari Rabu dan Jumat, sedangkan Manado ke Siau dan

Jadwal Pelayaran Kapal Penumpang

\begin{tabular}{|c|c|c|}
\hline $\mathrm{NO}$ & NAMA KAPAL & TUJUAN/RUTE/HARI \\
\hline 1. & KM. KARYA INDAH & $\begin{array}{l}\text { MANADO - TAHUNA( SETIAP HARI SENIN ) } \\
\text { MANADO - LIRUNG ( SETIAP HARI RABU - JUMAT ) }\end{array}$ \\
\hline 2. & KM. MARINA BAY I & $\begin{array}{l}\text { MANADO - SIAU- TAHUNA ( SETIAP HARI SENIN- } \\
\text { RABU-JUMAT) }\end{array}$ \\
\hline 3. & KM. EXPRESS BAHARI 2E & $\begin{array}{l}\text { MANADO-TAGULANDANG-SIAU-TAHUNA } \quad(\quad \text { SETIAP } \\
\text { HARI SENIN-RABU-JUMAT) }\end{array}$ \\
\hline 4. & KM. MAJESTIC KAWANUA II & $\begin{array}{l}\text { MANADO-TAGULANDANG-SIAU-TAHUNA } \quad(\quad \text { SETIAP } \\
\text { HARI SELASA-KAMIS-SABTU) }\end{array}$ \\
\hline 5. & KM. MAJESTIC KAWANUA & $\begin{array}{l}\text { MANADO-TAGULANDANG-SIAU-TAHUNA } \quad(\quad \text { SETIAP } \\
\text { HARI SENIN-RABU-JUMAT })\end{array}$ \\
\hline 6. & KM. ELIZABETH III & MANADO - TOBELO ( SETIAP HARI SENIN ) \\
\hline 7. & KM. GEOVANI & MANADO - TERNATE ( SETIAP HARI SELASA ) \\
\hline 8. & KM. BUNDA MARIA & MANADO - TERNATE ( SETIAP HARI MINGGU ) \\
\hline 9. & KM. AGIL PRATAMA 04 & MANADO - TERNATE ( SETIAP HARI SENIN ) \\
\hline 10. & KM. PERMATA BUNDA & MANADO - TERNATE ( SETIAP HARI MINGGU ) \\
\hline 11. & KM. PRIMA OASIS & $\begin{array}{l}\text { MANADO-TAGULANDANG-SIAU-TAHUNA } \quad(\text { SETIAP } \\
\text { HARI SELASA-KAMIS-MINGGU ) }\end{array}$ \\
\hline 12. & KM. MARIN TERATAI & MANADO - TERNATE ( SETIAP HARI RABU ) \\
\hline 13. & KM. HOLLY MARY & $\begin{array}{l}\text { MANADO - TALAUD ( SETIAP HARI RABU-JUMAT ) } \\
\text { MANADO-SIAU-TAHUNA ( SETIAP HARI MINGGU ) }\end{array}$ \\
\hline 14. & KM. TERRA SANCTA & $\begin{array}{l}\text { MANADO - SIAU (SETIAP HARI SENIN - RABU -JUMAT } \\
\text { MANADO-SIAU-TAHUNA ( SETIAP HARI MINGGU ) }\end{array}$ \\
\hline 15. & KM. SAINT MARY & $\begin{array}{l}\text { MANADO - TAHUNA ( SETIAP HARI SELASA-KAMIS- } \\
\text { SABTU ) }\end{array}$ \\
\hline 16. & KM. METRO TERATAI & $\begin{array}{l}\text { MANADO - TAHUNA (SETIAP HARI SELASA-KAMIS- } \\
\text { SABTU) }\end{array}$ \\
\hline 17. & KM. MERCY TERATAI & $\begin{array}{l}\text { MANADO - TAHUNA ( SETIAP HARI SENIN-RABU- } \\
\text { JUMAT ) }\end{array}$ \\
\hline
\end{tabular}

Tabel 1 : Jadwal Pelayaran Kapal di Pelabuhan Manado 
ke Tahuna dalam satu kali perjalanan setiap hari Minggu. Keempatbelas, KM.Terra Sancta berlayar dari Manado ke Siau setiap hari Senin, Rabu dan Jumat, sedangkan Manado ke Siau ke dan ke Tahuna dalam satu kali perjalanan setiap hari Minggu. Kelimabelas, KM.Saint Mary berlayar dari Manado ke Tahuna setiap hari Selasa, Kamis dan Sabtu. Keenambelas, KM.Metro Teratai berlayar dari Manado ke Tahuna setiap hari Selasa, Kamis dan Sabtu. Dan yang terakhir kapal yang ketujuh belas KM.Mercy Teratai berlayar dari Manado ke Tahuna setiap hari Senin, Rabu dan Jumat.

\section{Wawancara di Pelabuhan Manado}

Wawancara pertama didapati komoditi pertanian yang dibawa dari Sangihe ke Manado adalah Beras dan Pisang dan dibawa oleh 2 orang untuk dikonsumsi sekeluarga, tapi dalam wawancara narasumber tersebut mengatakan tidak hanya Beras dan Pisang yang biasa dibawanya, biasanya yang dibawahnya juga sayur-sayuran dan buah-buahan dan untuk yang dikirimkan dari Manado ke Sangihe adalah rempah-rempah yang dibutuhkan di kepulauan Sangihe.

Wawancara kedua narasumber yang berasal dari sangihe dan komoditi pertanian yang dibawanya adalah Nenas dan Langsat. Dan penjualan tersebut langsung dilakukan oleh narasumber tersebut dan tidak melewati semacam pengepul. Komoditi pertanian Nenas yang dibawa narasumber dari Sangihe ke Manado ada 100 biji Nenas dan Langsat sekitaran 1 karung. Narasumber mengatakan Nenas biasa dijual di kisaranRp5.000-Rp.50.000

Wawancara ketiga didapati 2 orang narasumber yang dari Manado mau menjual komoditi pertanian di Tahuna. Komoditi pertanian yang dibawa adalah Pisang dan Bete yang berjumlah 2 karung Pisang dan 4 karung untuk Bete. Komoditi pertanian tersebut langsung diambil dan tidak melalui perantara yang harganya bisa melonjak. Harga Pisang yang dijual berjumlah 1 karung seharga Rp.120.000 itu di harga maksimum.

Wawancara keempat narasumber membawa Komoditi Pertanian seperti : Semangka, Rempah-Rempah(rempah-rempah yang dimaksud adalah BARITO). Paling banyak yang dikirmkan adalah Rempah-Rempah tersebut, dikarenakan permintaan yang tinggi. Komoditi pertanian tersebut diambil dari pasar Manado dan dibawa ke Tahuna. Komoditi pertanian seperti
Cabai (Rica) dipasarkan dengan harga Rp.100.000, Tomat dipasarkan kalau lagi musiman bisa dijual Rp. $8.000 / \mathrm{kg}$, sedangkan bawang juga pada saat tidak musim sekitar Rp.8.000/kg juga.

\section{KESIMPULAN DAN SARAN}

\section{Kesimpulan}

Berdasarkan hasil penelitian yang saya teliti, sistem logistik yang ada di pelabuhan manado mengalami penurunan yang tidak terlalu drastis dan kenaikan yang sangat drastis di tahun 2015. Dan Arus penumpang di tahun 2011-2013 masih normal, tapi di tahun 2014 dan 2015 mengalami kenaikan yang drastis dikarenakan penumpang yang melonjak di tahun tersebut. Sistem logistik yang ada di Pelabuhan Manado juga sudah bisa dikategorikan lumayan baik karena pendataan barangnya sudah bagus tapi masih belum dirincikan barang pertanian yang dimuat, dan untuk peralatan sudah bisa dikatakan baik dilihat dari segi Pelabuhan Manado yang masih masuk dalam kategori Pelabuhan Penumpang, karena kapal-kapal yang sandar di Pelabuhan Manado sudah lumayan banyak dan akan ditambah seiring berjalannya waktu, dikarenakan semakin melonjaknya penumpang antar pulau dan barang-barangnya yang dibawa. Dan untuk dari segi fasilitas untuk penmupang Pelabuhan Manado sudah sangat baik, dikarenakan pembangunan infrastruktur untuk penumpang sudah dilakukan semenjak saya penelitian disana dan akhir penelitian sudah terlihat hasil dari pembangunan tersebut.

\section{Saran}

Pengelola Pelabuhan Manado disarankan untuk Menambah Jadwal Keberangkatan dan Kedatangan di Pelabuhan Manado disebabkan banyak permintaan penumpang untuk Berangkat ke pulau-pulau, memperbanyak bagasi yang tampung agar penumpang bisa membawa lebih banyak barang logistik yang di perlukan untuk pulau-pulau maupun sebaliknya di Manado dan agar semoga kedepannya jarak perjalanan yang di tempuh antar pulau bisa di persingkat agar bisa menghemat waktu, tapi tidak membuat kenyamanan penumpang terganggu. Untuk sejauh ini Pelabuhan Manado kalau di rata-ratakan mulai dari fasilitas, infrastruktur, kegiatan logistik, pengelolaan, dan pelayanannya sudah baik untuk masyarakat. Dan dilihat dari data yang saya ambil semakin ke 2017 semakin melonjak penumpang 
dan barang yang dibawa, pihak pengelola pelabuhan semoga bisa memperbanyak fasilitas yang ada di pelabuhan agar tidak terjadi membludaknya penumpang dan pengelola keteteran menghadapi hal tersebut, dikarenakan juga Pelabuhan Manado meski masih Pelabuhan Penumpang, tapi sudah banyak logistik yang masuk di Pelabuhan Manado ini, kalau tidak ditanggulangi banyak penumpang dan barang yang tidak bisa dimuat ke dalam kapal-kapal.

\section{DAFTAR PUSTAKA}

Ballou, Ronald H.,1992. “Business Logistics Management, 4thed., Prentice-Hall-, Inc. New Jersey".

Badan Pengkajian dan Pengembangan Kebijakan Perdagangan, Pusat Kebijakan Perdagangan Luar Negeri, (2012). "Kajian Kebijakan Penentuan Pelabuhan Tertentu Sebagai Pintu Masuk Impor Produk Tertentu".

Badan Nasional Penanggulangan Bencana, (2008). "Pedoman Manajemen Logistik Dan Peralatan Penganggulangan Bencana".

Burhan dkk, (2013). "Penerapan JIT (Just In Time) Untuk Pengendalian Persediaan Pada Sistem Logistik Di Perum Bulog Sub Divisi Regional Surabaya".

Chandra A, (2013). "Analisis Kinerja Distribusi Logistik Pada Pasokan Barang Dari Pusat Distribusi Ke Gerai Indomaret Di Kota Semarang".

Deputi Bidang Koordinasi Pangan Dan Sumber Daya Hayati Kementerian Koordinator Bidang Perekonomian Republik Indonesia, (2014). "Pengembangan Sistem Logistik Pangan (Peternakan)".

Falianty T.A, (2012). "Swasembada Versus Impor (Komoditas Pertanian Strategis)".

Fernandez, (2014). "Distribusi Logistik Pertanian (Sistem Logistik Agribisnis Amburadul), Bisnis Indonesia 13 Februari 2014”.
Fizzanty dan Kusnandar, (2012). "Pengelolaan Logistik Dalam Rantai Pasok Produk Pangan Segar di Indonesia. Pusat Penelitian Perkembangan IptekLembaga Ilmu Pengetahuan Indonesia".

Ghiani, G., Laporte, G., Musmanno R, (2004)." Introduction to Logistics System Planning and Control", England, Wiley

Hendayana R, (2012). "Penerapan Metode Regresi Logistik Dalam Menganalisis Adopsi Teknologi Pertanian".

Kementerian Pertanian (2015 ). "Rencana Strategis Kementerian Pertanian".

Perdana, (2016). "Sistem Logistik Pertanian (Supply Chain Indonesia)".

Peraturan Presiden Republik Indonesia Nomor 26 Tahun 2012 Tentang "Cetak Biru Pengembangan Sistem Logistik Nasional".

Pusat Penganekaragaman Konsumsi dan Keamanan Pangan, Badan Ketahanan Pangan, (2015). "Ketahanan Pangan dan Pertanian".

Pambudy R, (2008). "Ketahanan Pangan Dalam Sistem Dan Usaha Agribisnis : Pemberdayaan Petani Dan Organisasi Petani".

ProModel Corporation, (2011). "ProModel 2011 User Guide". Pro Model Corporation, 2011.

Sinaga, Pariaman (2008). "Menuju Pasar Yang Berorientasi Pada Perilaku Konsumen".

Setijadi (2009). "Handout Sistem Logistik". Universitas Widyatama Bandung.

.Wasistiono S, (2006). "Mekanisme Pengelolaan \& Pengendalian Barang Daerah (Manajemen Logistik)".

Wilkinson J, R. Rocha, (2008). "The AgroProcessing Sector: Empirical Overview, Recent Trends and Development Impacts. Plenary Paper: Global Agro-Industries Forum, April, 2008. India” 